\title{
THE EFFECT OF THERMAL PROCESSING AND CHEMICAL COMPOSITION ON SECONDARY CARBIDE PRECIPITATION AND HARDNESS IN HIGH-CHROMIUM CAST IRONS
}

\author{
M. Agustina Guitar (1), U. Pranav Nayak, Dominik Britz and Frank Mücklich \\ Department of Materials Science, Saarland University, Campus D3.3, 66123 Saarbrücken, Germany \\ Dominik Britz and Frank Mücklich \\ Material Engineering Center Saarland, Campus D3.3, 66123 Saarbrücken, Germany
}

Copyright $@ 2020$ The Author(s)

https://doi.org/10.1007/s40962-020-00407-4

\begin{abstract}
The excellent abrasion resistance of high-chromium cast irons (HCCIs) is given by an optimal combination of hard eutectic and secondary carbides (SC) and a supporting matrix. The tailoring of the microstructure is performed by heat treatments (HTs), with the aim to adjust the final properties (such as hardness and abrasion resistance). In this work, the influence of chemical composition on the microstructure and hardness of HCCI_26\%Cr is evaluated. An increase in the matrix hardness was detected after HTs

$850^{\circ} \mathrm{C}$. During subsequent heating up to $980^{\circ} \mathrm{C}$ and holding at this temperature, they transformed completely to $M_{23} C_{6}$. According to the MatCalc simulations, further precipitation of $M_{23} C_{6}$ occurred during cooling, in the temperature range $980-750{ }^{\circ} \mathrm{C}$. Both phenomena were related to experimental observations in samples quenched after 0-, 30-, 60- and 90-min destabilization, where $M_{23} C_{6}$ $S C$ were detected together with very fine $S C$ precipitated in areas close to eutectic carbides.
\end{abstract} resulting from combining precipitation of $M_{23} C_{6} S C$ during destabilization, and austenite/martensite transformation during quenching. Kinetic calculations of the destabilization process showed that $M_{7} C_{3}$ secondary carbides are the first to precipitate during heating, reaching a maximum at
Keywords: High chromium cast iron, Microstructure tailoring, Secondary carbide precipitation

\section{Introduction}

High-chromium cast irons (HCCIs) are used for wear-resistant components in the mining and mineral processing industries, given their outstanding wear and erosion resistance. ${ }^{1}$ HCCIs can be considered as composite materials, showing a structure composed of large eutectic $\mathrm{M}_{7} \mathrm{C}_{3}(\mathrm{M}$ : $\mathrm{Cr}-\mathrm{Fe}$ ) carbides embedded in a softer ferrous matrix, which could be austenitic in the as-cast condition or martensitic after a subsequent thermal treatment. ${ }^{2,3}$ The microstructure and mechanical properties of $\mathrm{HCCI}$ are a direct consequence of the eutectic carbide (EC) content, matrix microstructure and the presence of secondary carbides (SC) homogeneously

This paper is an invited submission to IJMC selected from presentations at the 2nd Carl Loper 2019 Cast Iron Symposium held September 30 to October 1, 2019, in Bilbao, Spain. distributed throughout the metallic matrix. ${ }^{4}$ Particularly, the presence of secondary carbides has shown to improve the wear resistance behavior of the whole "composite." ${ }^{5}$ Consequently, the properties of the material are dependent upon the volume fraction, size and distribution of the second phase ${ }^{6}$ and especially of the SC precipitated during thermal treatment. This controlled precipitation improves the mechanical properties of HCCI, mainly those related to friction reduction and abrasive wear resistance. ${ }^{7-9}$

The microstructure in HCCI can be modified through alloy design, processing route and heat treatments (HTs), which can include destabilization, sub-critical and quenching treatments, or a combination thereof. ${ }^{10,11}$ An optimal destabilization process is highly dependent on the temperature $\left(900-1150{ }^{\circ} \mathrm{C}\right.$ ) and holding time $(5 \mathrm{~min}$ to $8 \mathrm{~h}$ ), and thus, the used parameters together with the chemical 
composition (especially the $\mathrm{Cr} / \mathrm{C}$ ratio) will determine the type of SC. ${ }^{9,12-15}$ The parameters used during destabilization also determine the amount of carbon that remains in solution in the austenitic matrix and therefore the amount of retained austenite, its final hardness and subsequent resistance. ${ }^{14}$ Destabilization at higher temperatures leads to a reduction in the driving force for carbide precipitation, resulting in a lower Ms temperature, and therefore, a large amount of austenite will be retained within the martensitic matrix, with lower overall material hardness. ${ }^{14}$ On the other hand, destabilizing at lower temperatures results in an extensive precipitation of SC and a low-hardness martensite, as a consequence of the low carbon content. ${ }^{7,12,14-16}$

A sub-critical treatment, or tempering, is usually employed to reduce the amount of retained austenite (RA) and increase the spalling resistance. ${ }^{14,17}$ The final microstructure after tempering is highly dependent on the materials' chemical composition, temperature and time of the treatment and the prior thermal history. ${ }^{8,14}$ Typically, temperatures range between 200 and $650{ }^{\circ} \mathrm{C}$ and times up to 12 h. ${ }^{11,14}$ Excess of temperature or time results in softening and drastic reduction in abrasion resistance, whereas insufficient tempering results in incomplete elimination of austenite. $^{8}$ The sequence of the different steps in the heat treatment is also crucial in the resulting material. Applying a sub-critical treatment before or after a destabilization leads to a completely different final microstructure. ${ }^{11}$

As described, many parameters related to the HT play a fundamental role in the final microstructure of HCCI and thus in their mechanical response. By systematically varying and combining these parameters, a tailored microstructure might be obtained, which ensures the optimal balance between the tribological behavior and fracture toughness necessary for each particular case.

A multi-step HT was proposed by Guitar et al., ${ }^{9}$ where the sub-critical process is carried out directly following the destabilization of the austenite. Later, a second destabilization step was performed followed by a quenching in air. The implementation of this multi-step HT to HCCI_16\% Cr showed an improvement of $69 \%$ in the wear resistance in comparison with the destabilized and quenched material.

The objective of the present work is, on the one hand, to implement the same multi-step HT previously applied in HCCI_16\% Cr to a HCCI containing a higher amount of $\mathrm{Cr}$ $(26 \%)$ in order to evaluate the influence of the chemical composition, especially the $\mathrm{Cr}$ content, in the final microstructure. On the other hand, this work intends to evaluate the influence of varying some parameters at different stages of the HT in the SC precipitation. Finally, the first attempts in the implementation of thermodynamic and kinetic calculations for microstructural design will be detailed and correlated to the experimentally obtained results. Specifically, the holding time during the destabilization will be modified, to evaluate its influence on the SC size and fraction.

\section{Experimental}

HCCI samples were manufactured in an arc furnace and cast in cubic sand molds. Chemical composition was determined by emission spectroscopy methods using a GNR Metal Lab 75/80 Optical Emission Spectroscope. The chemical composition of the studied HCCI is: C

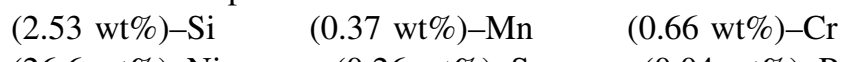
$(26.6 \mathrm{wt} \%)-\mathrm{Ni} \quad(0.26 \mathrm{wt} \%)-\mathrm{S} \quad(0.04 \mathrm{wt} \%)-\mathrm{P}$ $(<0.01 \mathrm{wt} \%)-\mathrm{Cu}(0.03 \mathrm{wt} \%)-\mathrm{Fe}$ (balance). The as-cast microstructure is composed of $(\mathrm{Fe}, \mathrm{Cr})_{7} \mathrm{C}_{3}$ eutectic carbides (EC) embedded in an austenitic matrix. In addition to the major phases, austenite and $\mathrm{M}_{7} \mathrm{C}_{3} \mathrm{EC}$, a thin layer of martensite is present at the periphery of the carbides. The martensite formation is associated with the local $\mathrm{C}$ and $\mathrm{Cr}$ depletion which takes place during the solidification of the EC in contact with the pro-eutectic austenite.

The multi-step HT described in Refs. ${ }^{9,18}$ was applied to the HCCI_26\%Cr in order to evaluate the applicability of a successful HT to a material with the different chemical composition and therefore evaluate the influence to the $\mathrm{Cr}$ content in the modified microstructure. The multi-step HT includes destabilization at $980{ }^{\circ} \mathrm{C}$ for $1.5 \mathrm{~h}$, sub-critical diffusion (SCD) step at $650{ }^{\circ} \mathrm{C}$ for $12 \mathrm{~h}$ [followed by air cooling until room temperature (RT)] and a final destabilization $\left(980^{\circ} \mathrm{C} / 1.5 \mathrm{~h}\right)$ and quenching (air quenched) step. In this work, samples in three different states are evaluated: (1) sample Q: destabilized $\left(980{ }^{\circ} \mathrm{C} / 1.5 \mathrm{~h}\right)+$ quenching; (2) sample SCD: destabilized $\left(980{ }^{\circ} \mathrm{C} / 1.5 \mathrm{~h}\right)+$ sub-critical diffusion $\left(650{ }^{\circ} \mathrm{C} / 12 \mathrm{~h}\right)$ and (3) sample $\mathrm{SCD}+\mathrm{Q}$ : a combination of the two previous. Additionally, and in order to evaluate the influence of destabilization holding time on the SC fraction and size, another set of samples was destabilized at $980{ }^{\circ} \mathrm{C}$ for different times $(0,0.5,1 \mathrm{~h})$ and air cooled to RT.

The samples were ground with embedded SiC disks (up to grit 1200) and polished using diamond powder suspensions up to $1 \mu \mathrm{m}$ mean diameter. The samples were etched with Vilella's reagent $(1 \mathrm{~g}$ picric acid $+5 \mathrm{~mL} \mathrm{HCl}+95 \mathrm{~mL}$ $\left.\mathrm{C}_{2} \mathrm{H}_{5} \mathrm{OH}\right)$ for microstructural characterization and with a variation of Murakami's reagent $\left(4 \mathrm{~g} \mathrm{~K}_{3}\left[\mathrm{Fe}(\mathrm{CN})_{6}\right]+8 \mathrm{~g}\right.$ $\mathrm{NaOH}+100 \mathrm{~mL} \mathrm{H} \mathrm{H}_{2} \mathrm{O}$ ) for $15 \mathrm{~s}$ at RT for the calculation of carbide volume fraction (CVF) and size of the SC. In all cases, the samples were immersed in the etchant for the appropriate time, rinsed with water and ethanol and air dried.

SEM characterization was carried out with a FE-SEM Helios Nanolab 600 (FEI company) working with an acceleration voltage of $10 \mathrm{kV}$ and a $1.4 \mathrm{nA}$ beam current. For a proper contrast between phases, a high-sensitivity 
solid-state backscattered electrons detector (vCD) was used. The size and volume fraction (VF) of the SC were determined using the image analysis software, ImageJ. ${ }^{19}$ 10-12 micrographs were considered for each sample, and the average was calculated. Phase identification was performed using a PANalytical Empyrean X-ray diffractometer coupled with a Co source, an acceleration voltage of $40 \mathrm{kV}$ and a $40 \mathrm{~mA}$ tube current. Secondary carbides identification was performed by transmission electron microscope (TEM) using a JEOL JEM-2010F equipment with a field emission gun operating at $80-200 \mathrm{kV}$. It is equipped with an imaging spherical aberration corrector (CEOS), an Oxford INCA Energy TEM 200 EDS system, a high-angle annular dark field detector, a Gatan annular dark field/bright field STEM detector, as well as a Gatan Tridiem image filter system. The TEM samples were prepared with focus ion beam (FIB-Helios Nanolab 600-FEI Company) as detailed in Reference 20.

For thermodynamic and kinetic calculations, the software MatCalc v.6.03 with the thermodynamic and diffusion databases "ME_Fe 1.2" and "ME_Fe 1.1," respectively, was used. The chemical composition of the matrix, measured using electron probe microanalysis (EPMA), was used as the input to the calculations: $\mathrm{C}(0.43 \mathrm{wt} \%)-\mathrm{Si}$ (0.36 wt $\%)-\mathrm{Mn} \quad(0.66 \mathrm{wt} \%)-\mathrm{Cr} \quad(18.2 \mathrm{wt} \%)-\mathrm{Ni}$ (0.20 wt\%)-Fe (balance). Two precipitate domains, austenite and martensite, and two precipitate phases, $M_{7} C_{3}$ and $\mathrm{M}_{23} \mathrm{C}_{6}$, were initially created. The HT cycle included a continuous heating from RT to $980{ }^{\circ} \mathrm{C}$ at a rate of $0.5^{\circ} \mathrm{C} / \mathrm{s}$, holding at various times $(0 \mathrm{~min}, 30 \mathrm{~min}, 60 \mathrm{~min}$ and $90 \mathrm{~min}$ ) and finally cooling to RT at a rate of $1{ }^{\circ} \mathrm{C} / \mathrm{s}$. The initial domain was set to austenite, whereas during the cooling stage, at $210{ }^{\circ} \mathrm{C}$, the domain was changed to martensite as dilatometry studies indicated an austenite to martensite transformation around this temperature for a cooling rate of $1{ }^{\circ} \mathrm{C} / \mathrm{s}$.

\section{Results and Discussion}

\section{Multi-step Heat Treatment}

The microstructure of the HCCI_26\%Cr samples was evaluated after the different stages of the multi-step HT, i.e., in the $\mathrm{Q}, \mathrm{SCD}$ and $\mathrm{SCD}+\mathrm{Q}$ states, as previously described. The SCD sample was subjected to a destabilization, followed directly by a sub-critical diffusion step and finally slow cooled until room temperature. The $\mathrm{Q}$ sample was destabilized and quenched in air, and the $\mathrm{SCD}+\mathrm{Q}$ was subjected to the whole multi-step HT (i.e., destabilization, sub-critical diffusion and posterior quenching). Temperatures, heating/cooling rate and holding times used for the different HT steps, as described in "Experimental" section, are the same as previously applied for the HCCI_16\%Cr. .,21 $^{9}$
Comparing the results corresponding to HCCI_26\%Cr with the previously obtained in HCCI_16\% Cr, ${ }^{9,21}$ some differences can be appreciated, principally related to the precipitated SC. For instance, in HCCI_16\% Cr only rounded $\mathrm{M}_{7} \mathrm{C}_{3}$ carbides were observed after all the heat treatment steps, whereas for the HCCI_26\%Cr, different types of carbides were identified depending on the thermal processing, as shown in Figure 1.

In the $\mathrm{Q}$ sample (Figure $1 \mathrm{~b}$ ), square-shaped $\mathrm{M}_{23} \mathrm{C}_{6}$ carbides (white arrows) can be observed together with some small carbides at areas in contact with the eutectic carbides (red arrows). The latter show a different contrast in the backscatter (BSE) mode images, which might indicate that they possess different chemical composition than the already identified $\mathrm{M}_{23} \mathrm{C}_{6}$ carbides. After quenching in air, the matrix transformed to martensite due to a reduction of $\mathrm{C}$ content in the austenitic matrix as shown in Figure 2a, which allows the martensite start temperature (Ms) to increase.

After the SCD step (Figure 1a), square-shaped carbides of $\mathrm{M}_{23} \mathrm{C}_{6}$ type (white arrows) precipitated during destabilization, together with some rod-like $\mathrm{Fe}_{3} \mathrm{C}$ carbides precipitated during the SCD step (blue arrows) embedded in a ferritic matrix (Figure 2a), were observed. In the case of HCCI_16\% Cr, no evidence of $\mathrm{Fe}_{3} \mathrm{C}$ formation during the SCD step was found, with $\mathrm{M}_{7} \mathrm{C}_{3}$ being the only carbide type detected.

In the $\mathrm{SCD}+\mathrm{Q}$ sample (Figure 1c), it is possible to observe the square-shaped carbides of the $\mathrm{M}_{23} \mathrm{C}_{6}$ type (white arrows) embedded in a martensitic matrix (Figure $2 \mathrm{a}$ ). In contrast to sample $\mathrm{Q}$, the $\mathrm{M}_{23} \mathrm{C}_{6}$ carbides are aligned forming a grid-like pattern (Figure 1c).

The $\mathrm{M}_{23} \mathrm{C}_{6}$ square-shaped carbides observed in all of the samples were precipitated during the destabilization process and were identified by TEM diffraction, as shown in Figure 2b. Rod-like carbides observed in SCD sample were not possible to be identified using TEM, due to their size and the insufficient resolution of the equipment used in this work. However, their morphology (Fig. 1a) is typically the pearlite microstructure. Furthermore, the $\mathrm{M}_{23} \mathrm{C}_{6}$ and $\mathrm{Fe}_{3} \mathrm{C}$ secondary carbides were not possible to be unambiguously identified using XRD, since their phase fraction is too low compared to the matrix and eutectic carbides, and thus, their diffraction peaks are located within the background noise. Moreover, the peaks for the different carbide types overlap, making their identification arduous. For these reasons, combining different characterization techniques, such as SEM and XRD, is highly valuable for the identification of secondary carbides.

As previously described, HCCI_16\%Cr showed the presence of only $\mathrm{M}_{7} \mathrm{C}_{3}$, independent of the HT applied. ${ }^{9}$ Based on that, it is clear that the chemical composition of HCCI 

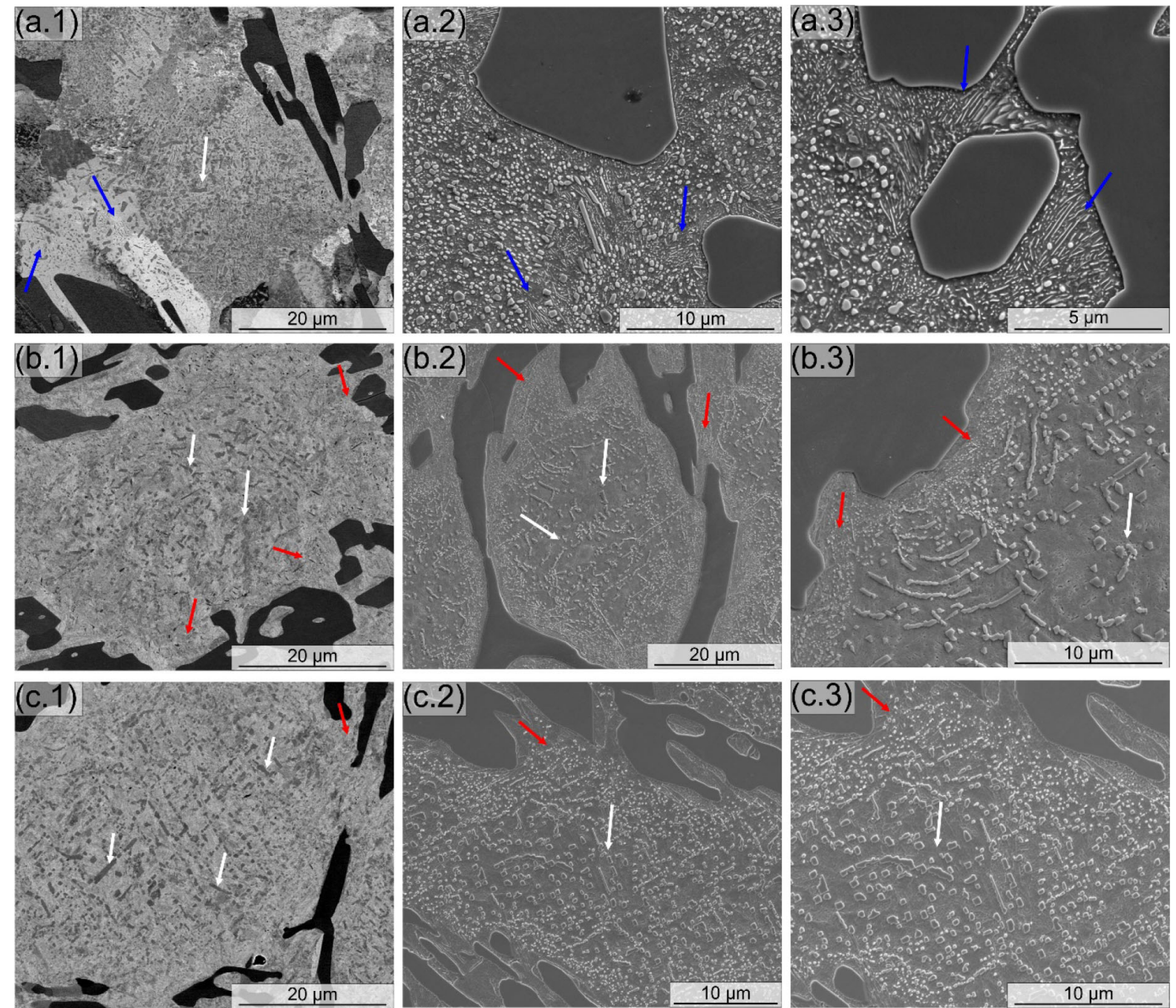

Figure 1. SEM images of the heat-treated samples: (a) $S C D$, (b) $Q$ and (c) $S C D+Q$. Images a.1), b.1) and c.1) correspond to BSE mode.

strongly influenced the nature and type of the secondary carbides precipitated during the different stages of HT. Moreover, it is evident that it is not possible to directly transfer a successful heat treatment from one material composition to another, and the heat treatment must be designed for each case in particular.

Microstructural modification plays a fundamental role in the mechanical response of the material. The latter highly depends on the type, morphology and distribution of carbides, and on the nature of the supporting matrix. Even in cases where the microstructural constituents are of similar nature, the thermal history influences the final mechanical response, as was the case for HCCI_16\% $\mathrm{Cr}$ in the Q and $\mathrm{SCD}+\mathrm{Q}$ states. ${ }^{9}$ Figure 3 shows the microhardness of the heat-treated HCCI_26\% $\mathrm{Cr}$ measured in the region of matrix, i.e., the EC were not included in the indentation. A hardness increment is observed in the Q (757 HV0.1) and SCD + Q (862 HV0.1) samples compared to as-cast material (360 HV0.1), which is related to the carbide precipitation and the austenite/martensite transformation. Moreover, a decrease in hardness of about $10 \%$ in comparison with the as-cast is observed in the SCD sample, which is related to the ferritic matrix, which is much softer than austenite or martensite. Additionally, the $\mathrm{Fe}_{3} \mathrm{C}$ carbides that precipitated during this stage offer less resistance than the $\mathrm{M}_{23} \mathrm{C}_{6}$ carbides observed in the $\mathrm{Q}$ and $\mathrm{SCD}+\mathrm{Q}$ samples.

Although the SC precipitation of the $\mathrm{M}_{7} \mathrm{C}_{3}$ or $\mathrm{M}_{23} \mathrm{C}_{6}$ type is beneficial for improving the material hardness and its abrasion resistance, ${ }^{14,22}$ the role of the matrix in the mechanical properties must be taken into account, since it acts as a mechanical support to the carbides. ${ }^{9}$ An improvement in wear resistance was previously observed in HCCI_16\% Cr after SCD + Q in comparison with Q treatment ${ }^{9}$ for microhardness values of the same magnitude (770 \pm 10 and $745 \pm 26$ HV0.5, respectively), which was not possible to be directly addressed to the material hardness or size of SC, whereas in the case of 

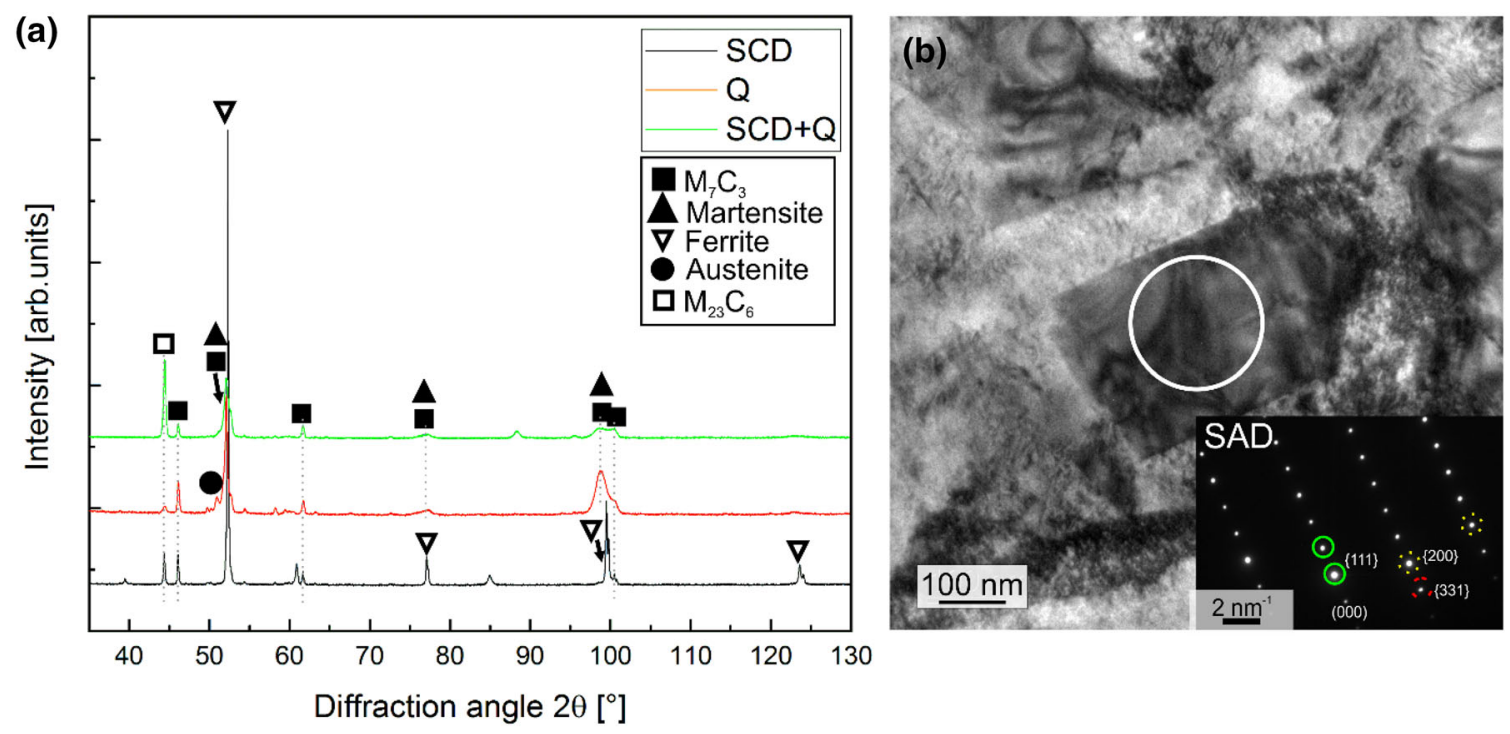

Figure 2. (a) XRD of the samples after different heat treatment steps. It shows that a martensitic matrix is obtained after $Q$ and $S C D+Q$ treatments, whereas ferritic matrix is present after $S C D$ treatment; (b) TEM bright field image and selected area diffraction (SAD) of the square-shaped secondary carbides, identified as $M_{23} C_{6}$.
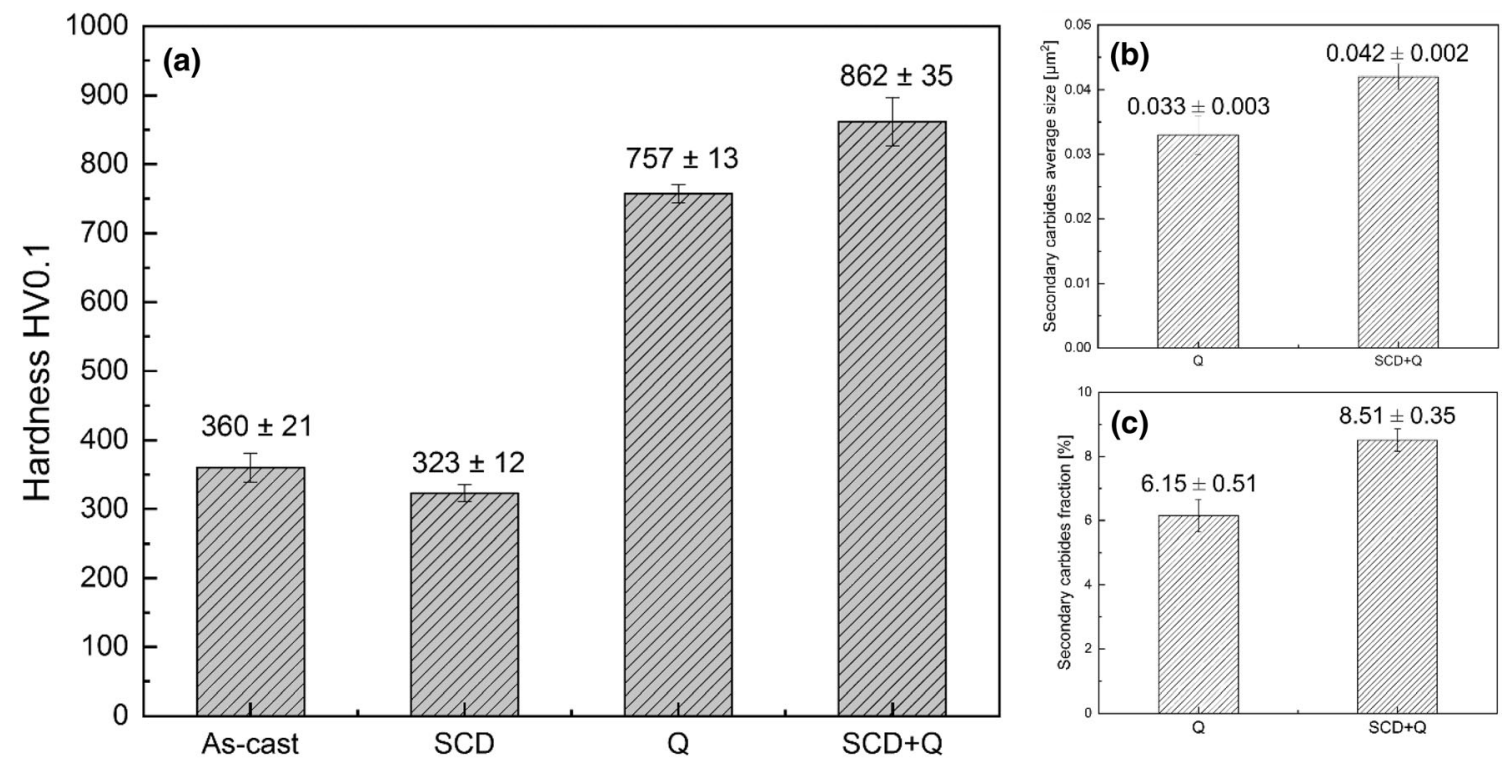

Figure 3. (a) Microhardness (HV0.1) of the as-cast and heat-treated samples; (b) average size of the secondary carbides corresponding to samples $Q$ and $S C D+Q ;$ (c) volume fraction of the secondary carbides corresponding to the $Q$ and $S C D+Q$ samples.

HCCI_26\%Cr, a difference in hardness is already noticeable between SCD + Q and Q samples, being higher for the SCD $+\mathrm{Q}$ one (Figures 3b, 3c). This difference might be related to the size of the $\mathrm{SC}$, the martensitic matrix properties or a combination thereof.

For optimal abrasion resistance, $\mathrm{SC}$ of the $\mathrm{M}_{3} \mathrm{C}$ type, as those found in the SCD sample, are not desired since they offer less resistance to deformation. ${ }^{23}$ However, the precipitation of this type of carbides during intermediate steps might be beneficial for obtaining a tailored microstructure for proper abrasion response. As shown in Figure 1, the $\mathrm{SCD}+\mathrm{Q}$ sample shows the SC forming a grid-like pattern, which cannot be observed in the $\mathrm{Q}$ sample. This can indicate that the SCD step might allow the redistribution of the alloy elements, with the addition that the $\mathrm{M}_{3} \mathrm{C}$ carbides might act as precursors for the formation $\mathrm{M}_{23} \mathrm{C}_{6}$ during the subsequent HT steps through the diffusion of $\mathrm{Cr}^{24}{ }^{24}{ }^{25}$ which might be the case for HCCI_26\% Cr since after the complete thermal cycle (i.e., $\mathrm{SCD}+\mathrm{Q}$ ), only $\mathrm{M}_{23} \mathrm{C}_{6}$ carbides were detected. 


\section{Implementation of Kinetics Calculations for Microstructure Tailoring}

Several research works concerning the effect of thermal treatment and chemical composition on the microstructure and properties of HCCI have been carried out, ${ }^{3,8,9,14-16,26}$ with the efforts only focused on the formation, type and morphology of the secondary carbides precipitated after the heat treatments. Experimental tailoring of the microstructure is tedious and resource intensive, since there are countless number of parameters that can be modified and added to all possible combinations. For this reason, the first approaches in the implementation of kinetic calculations for the design of a proper HT for a microstructure tailoring are presented in this work. As a starting point, the destabilization process followed by a quenching step was simulated in MatCalc for the evaluation of carbide precipitation during this process. The starting of the SC precipitation and the effect of the holding time in the type and SC volume fraction at the destabilization temperature were evaluated.

Figure 4 shows the SC phase fraction during destabilization process at $980{ }^{\circ} \mathrm{C}$ for 0,30 and $90 \mathrm{~min}$ calculated using MatCalc. Simulated results show two clearly separated processes. The first one, occurring during heating, indicates that the precipitation of SC starts with the formation of $\mathrm{M}_{7} \mathrm{C}_{3}$ carbides, which reaches a maximum at a temperature of around $850{ }^{\circ} \mathrm{C}$. From this point onward, simulations show carbides of the $\mathrm{M}_{23} \mathrm{C}_{6}$ type, which seems to occur at the expense of the $\mathrm{M}_{7} \mathrm{C}_{3}$. When the temperature reaches $980{ }^{\circ} \mathrm{C}$, almost all $\mathrm{M}_{7} \mathrm{C}_{3} \mathrm{SC}$ have either dissolved or transformed to $\mathrm{M}_{23} \mathrm{C}_{6}$ and after that, during holding, only carbides of this type can be found. A small fraction of $\mathrm{M}_{7} \mathrm{C}_{3}$ carbides is still present in the sample quenched directly after heating, presumably due to insufficient time for $\mathrm{M}_{7} \mathrm{C}_{3}$ to $\mathrm{M}_{23} \mathrm{C}_{6}$ transformation. No further SC precipitation is observed during soaking (given by a constant phase fraction) until cooling, where the second interesting process is observed. At this point, and in the range of temperatures between 980 and $750{ }^{\circ} \mathrm{C}$, further $\mathrm{M}_{23} \mathrm{C}_{6} \mathrm{SC}$ precipitation takes place, given by the increase in the phase fraction of $\mathrm{M}_{23} \mathrm{C}_{6}$. The carbides precipitating in this range during simulations might correspond to those small carbides observed in SEM images at the areas in contact with the eutectic carbides (red arrow in Figure 1b), since they are much smaller than the $\mathrm{M}_{23} \mathrm{C}_{6} \mathrm{SC}$ precipitated in the middle of the matrix, and thus, they probably precipitated later during the HT not having time to grow or coalesce.

Some studies have shown that carbides usually form by following a reaction sequence $\mathrm{M}_{3} \mathrm{C} \rightarrow \mathrm{M}_{7} \mathrm{C}_{3} \rightarrow$ $\mathrm{M}_{23} \mathrm{C}_{6} \cdot{ }^{24,25}$ In this case, the destabilization temperature is too high for the presence of $\mathrm{M}_{3} \mathrm{C}$, reason why it is not seen as the precursor for the $\mathrm{M}_{7} \mathrm{C}_{3}$ formation. Inoue-Masumoto $^{25}$ showed the in situ transformation of $\mathrm{M}_{7} \mathrm{C}_{3}$ to $\mathrm{M}_{23} \mathrm{C}_{6}$ when annealing a $18.6 \mathrm{wt} \% \mathrm{Cr}-3.40 \mathrm{wt} \% \mathrm{~W}-$
$3.63 \mathrm{wt} \% \mathrm{C}$ steel tempered for $10 \mathrm{~h}$ at $700{ }^{\circ} \mathrm{C}$. No apparent specific crystallographic relationship between the lattices of both carbides was observed, and thus, the $\mathrm{M}_{7} \mathrm{C}_{3} \rightarrow$ $\mathrm{M}_{23} \mathrm{C}_{6}$ transformation occurs through the diffusion of alloying elements from the matrix and the former carbides to the resultant carbides, or that of carbon from the former carbides to the matrix is thought to be rate controlling.

After the implementation of the kinetic calculations, experimental HT was performed for the corroboration of the theoretical results. For that, the holding time at the destabilization temperature was varied from 0 to $90 \mathrm{~min}$, and later, the samples were air quenched. Figure 5 shows the microstructure for the different holding times, 0, 30, 60 and $90 \mathrm{~min}$. In all cases, $\mathrm{M}_{23} \mathrm{C}_{6} \mathrm{SC}$ were detected using the same methodology as previously described for samples in Figure 1, showing larger sizes at the central region of the matrix and very small carbides in the area in contact with the eutectic carbides. The latter might correspond, again, to SC precipitated during the cooling. Phase identification in Figure 6 shows the final microstructure being martensite with some fraction of retained austenite, which is expected to be larger in the samples destabilized for shorter times.

The size and fraction of secondary carbides were determined by I-A using the software Image $\mathrm{J}^{19}$ and are displayed in Figure 7. It shows that the average particle size increases with the holding time, supporting the fact that during holding, the SC fraction remains unchanged and only SC growth is occurring, as suggested by the kinetic calculations (Figure 4). However, only a slight difference in size can be seen when destabilizing for 60 and $90 \mathrm{~min}$. The same tendency is shown in the carbide volume fraction, suggesting a steady state in the precipitation and growth of SC after $60 \mathrm{~min}$ of destabilization. Fraction of SC calculated from IA for 60 and 90 min shows a good correlation with the fraction predicted by the simulations in Figure 4. However, for shorter holding time ( 0 and $30 \mathrm{~min}$ ) the prediction seems not to correlate well with the experimental results. One of the reasons might be related to the presence of very small carbides not detected during the metallographic characterization, leading to the calculation of smaller carbide fraction.

Even though destabilization treatments are a common practice in the hardening of $\mathrm{HCCI}$, there are still some discussions concerning the exact occurrence of SC precipitation. It was suggested that the SC precipitate within the first $15 \mathrm{~min}$ of the treatment as a result of re-ordering of the carbon within the austenitic matrix, ${ }^{12}$ and holding for longer times would lead to coarsening of the carbides. The results shown here are not only in accordance with this assumption, but they also suggest that the precipitation starts even during heating. Moreover, it seems that the growth of SC reaches a steady state at some point, which is assumed to be after 60-min destabilization. Other authors suggested that nucleation also occurs during the cooling 


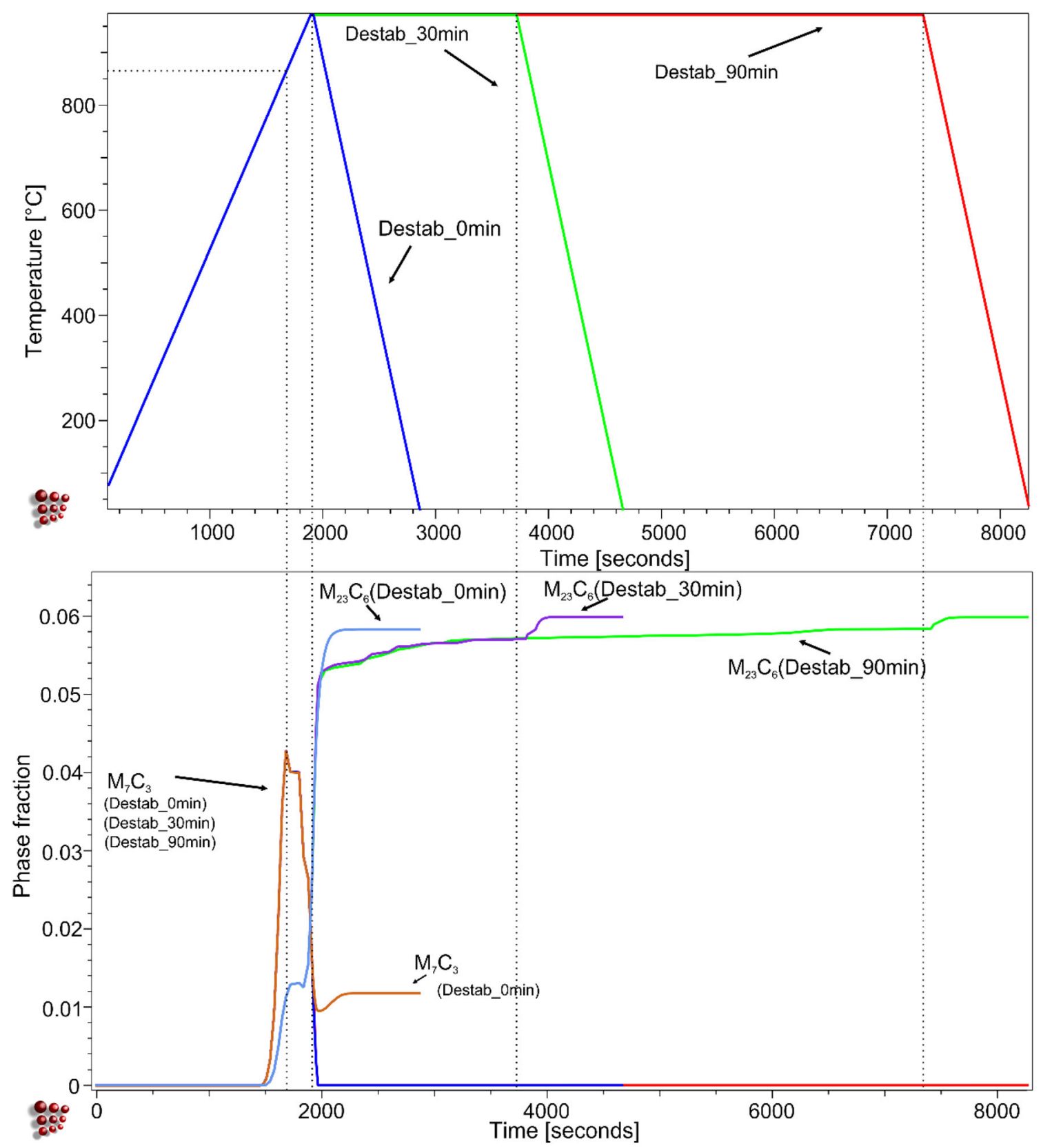

Figure 4. Destabilization process at $980^{\circ} \mathrm{C}$ for different times (0,30 and $\left.90 \mathrm{~min}\right)$ calculated using MatCalc and the corresponding SC type and fraction. Thermal cycle for the destabilization process (on top) and the SC type and fraction during HT as a function of time (low).

process, after detecting much finer $\mathrm{M}_{23} \mathrm{C}_{6} \mathrm{SC}$ after quenching to a cryogenic temperature. ${ }^{27}$ This suggestion might also be upheld by the kinetic calculations and microstructural analysis, where the increase in SC volume fraction during cooling shown in Figure 4 is supported by the presence of very small SC in Figures $1 \mathrm{~b}$ and 5.

After the destabilization for different times, microhardness measurements (Figure 8) were carried out in order to evaluate the influence of the holding time on the mechanical response. The lower microhardness value (Figure 8) for the sample Destab_0min is related to the lower SC size and volume fraction shown in Figure 7 , whereas the sample Destab_90min showing the highest hardness value corresponds to the highest volume fraction and largest SC size. Additionally, the amount of retained austenite (RA) is also expected to vary with the holding time, ${ }^{28}$ where the sample destabilized for 0 min should contain the largest amount of RA due to the still large amount of carbon within the matrix. Therefore, both the matrix, and volume fraction and size of SC play together for the final hardness value. ${ }^{28}$

The tendency is that the longer the holding times at the destabilization temperature, the higher the hardness ${ }^{10}$. It also can be related to the $\mathrm{SC}$ precipitation process. The 

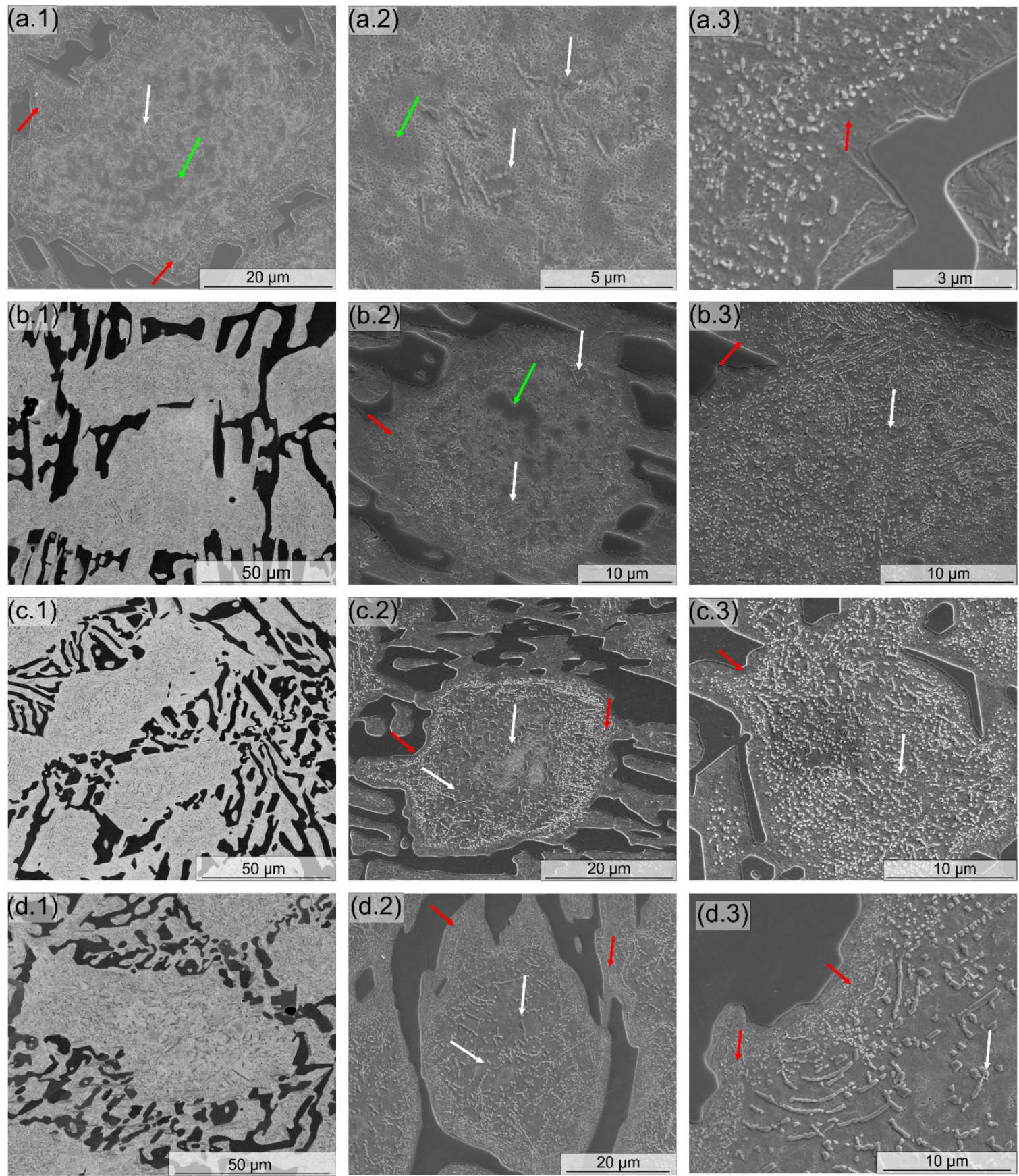

Figure 5. Samples destabilized at $980^{\circ} \mathrm{C}$ for different times, (a) 0 , (b) 30 , (c) 60 and (d) 90 min. Images d.1-d.3 are the same as previously shown in Figure 1, which were included here for reference.

soaking time for reaching the maximum hardness is highly dependent on the destabilization temperature. ${ }^{28}$ After that, the hardness starts to decrease as a consequence of coalescence and dissolution of SC, as explained by BedollaJacuinde. ${ }^{28}$ Figures 7 and 8 show almost no difference in the microhardness and SC volume fraction values for the samples destabilized for 60 and 90 min, which might indicate the reaching of a steady state in the hardening of the material. However, destabilization for longer times should be performed for assuring the soaking time for maximum hardness, which is not the objective of the present work. Besides the hardness, also the tribological response of the material might be altered by the soaking time, since it will control the carbon content in the martensite after quenching. This is the critical point which must be examined in detail, since the characteristic of the matrix supporting the carbides will determine the final response of the material. 


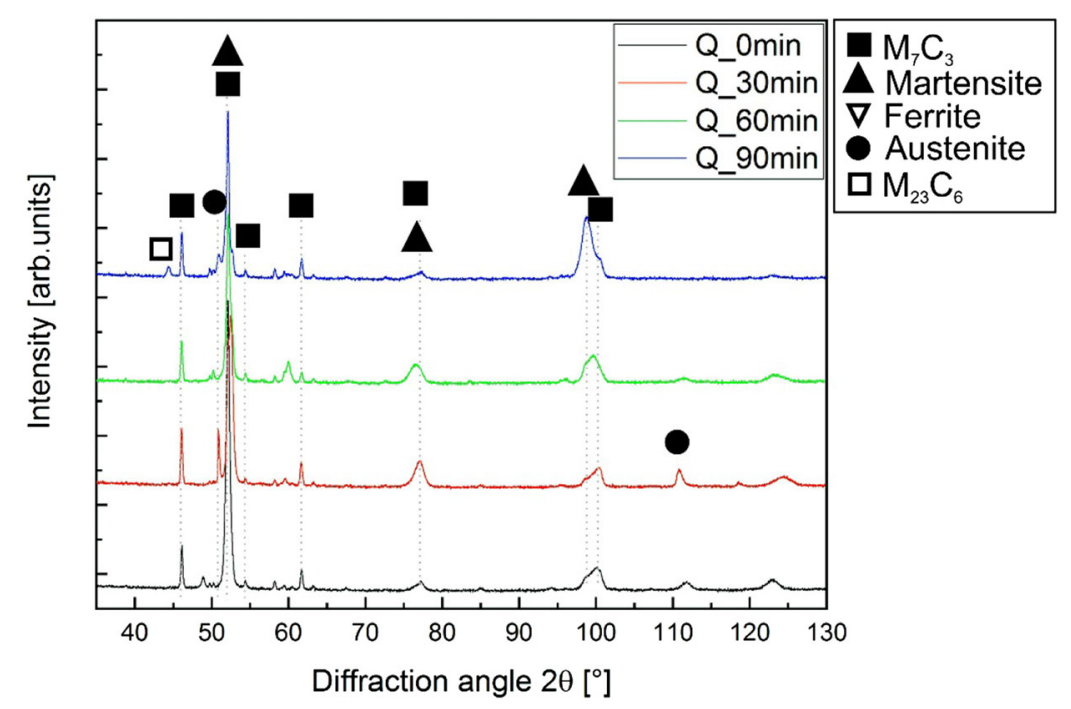

Figure 6. XRD of the samples destabilized for different times.

(a)

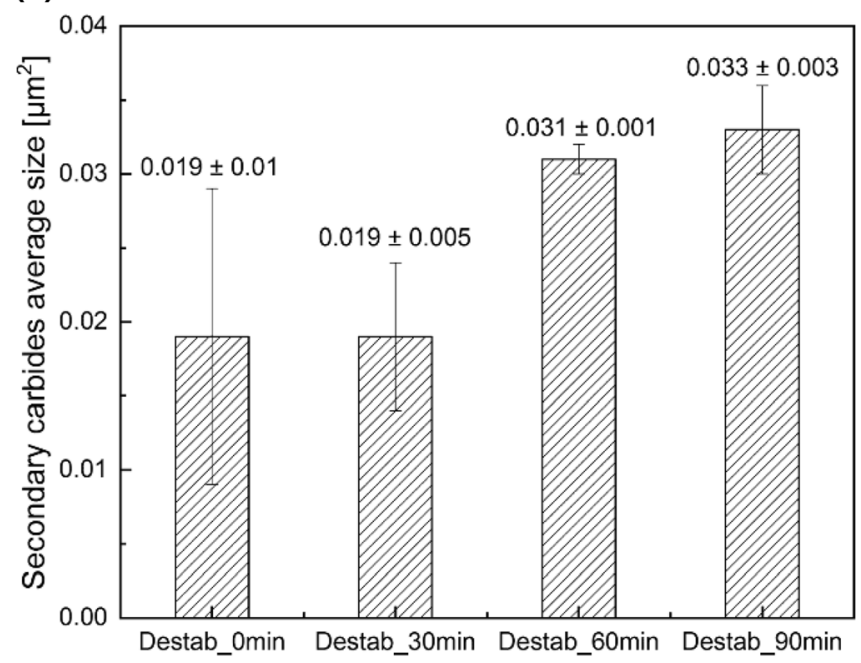

(b)

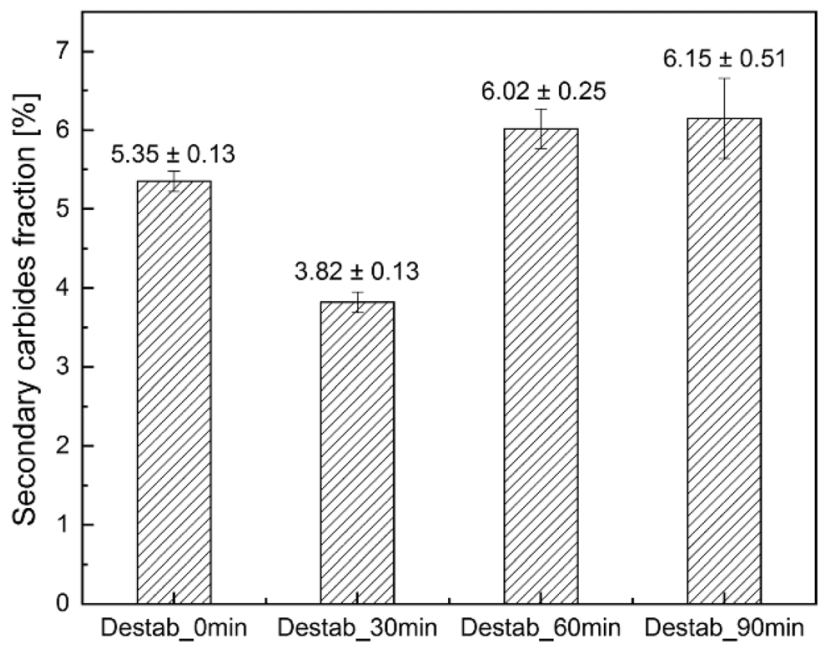

Figure 7. (a) Size and (b) volume fraction of secondary carbides after destabilization at 0, 30, 60 and 90 min.

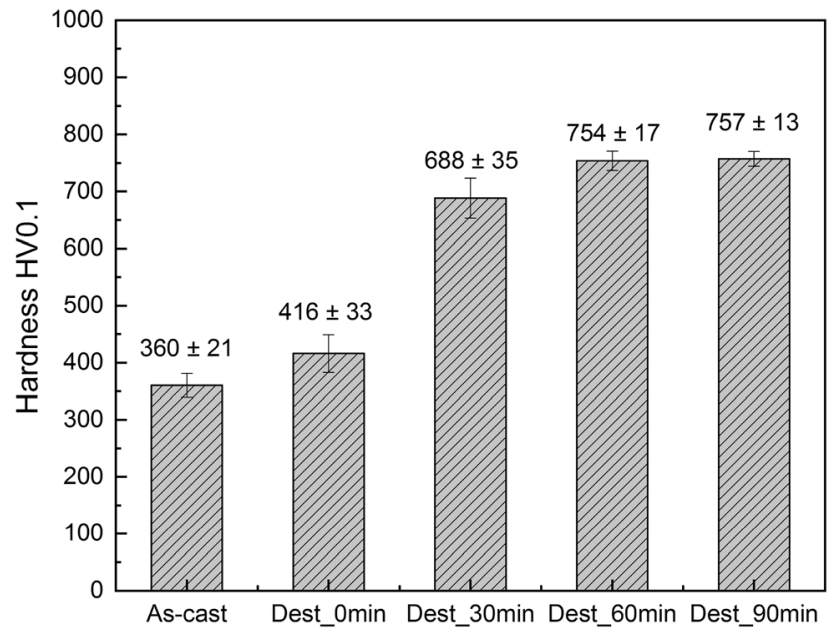

Figure 8. Microhardness (HV0.1) of the samples destabilized at $980^{\circ} \mathrm{C}$ for $0,30,60$ and $90 \mathrm{~min}$.

\section{Conclusions}

In this work, we evaluated the influence of the chemical composition, especially the $\mathrm{Cr}$ content, in the microstructure after employing a multi-step HT that was successfully applied in HCCI_16\%Cr. It was observed that the $\mathrm{Cr}$ content influences the nature of the SC precipitated during the different steps of the $\mathrm{HT}$, changing from $\mathrm{M}_{7} \mathrm{C}_{3}$ to $\mathrm{M}_{23} \mathrm{C}_{6}$ when $\mathrm{Cr}$ increases. SCD treatment led to a microstructure composed by ferrite, $\mathrm{M}_{3} \mathrm{C}$ and $\mathrm{M}_{23} \mathrm{C}_{6}$. Q and $\mathrm{SCD}+\mathrm{Q}$ produced $\mathrm{M}_{23} \mathrm{C}_{6} \mathrm{SC}$ embedded in a martensitic matrix, obtained after quenching.

Microhardness followed the same tendency than that observed in HCCI_16\%Cr. ${ }^{9}$ The sample with ferritic matrix showed the lowest hardness value. Variations in the values for Q and SCD + Q were observed, which might be 
related to the size of the SC. However, the influence of the supporting matrix must not be dismissed, since the SCD might be beneficial for the alloy elements partitioning.

Samples destabilized for 60 and 90 min showed almost no difference in the microhardness and SC volume fraction values, which might indicate the reaching of a steady state in the hardening of the material. However, destabilization for longer times should be performed for assuring the soaking time for maximum hardness, which was not the objective of the present work.

Thermodynamic and kinetic calculations of the destabilization process showed that $\mathrm{M}_{7} \mathrm{C}_{3}$ are the first to precipitate during heating. After destabilization temperature is reached, they completely transform to $\mathrm{M}_{23} \mathrm{C}_{6}$, which grow throughout the holding time. Further precipitation of $\mathrm{M}_{23} \mathrm{C}_{6}$ occurred during cooling, in the temperature range $980-750{ }^{\circ} \mathrm{C}$. The SC precipitated at this point are observed in the quenched samples in the area in contact with the EC.

\section{Acknowledgements}

Open Access funding provided by Projekt DEAL. The authors wish to acknowledge the EFRE Funds (C/4EFRE-13/2009/Br) of the European Commission for supporting activities within the AME-Lab project and would also like to thank Dr. Martín Duarte Guigou from Universidad Católica del Uruguay and Tubacero S.A. for providing the material. P. Nayak wishes to thank the German Academic Exchange Service (DAAD) for their financial support.

Open Access This article is licensed under a Creative Commons Attribution 4.0 International License, which permits use, sharing, adaptation, distribution and reproduction in any medium or format, as long as you give appropriate credit to the original author(s) and the source, provide a link to the Creative Commons licence, and indicate if changes were made. The images or other third party material in this article are included in the article's Creative Commons licence, unless indicated otherwise in a credit line to the material. If material is not included in the article's Creative Commons licence and your intended use is not permitted by statutory regulation or exceeds the permitted use, you will need to obtain permission directly from the copyright holder. To view a copy of this licence, visit http://creativecommons. org/licenses/by/4.0/.

\section{REFERENCES}

1. R.J. Llewellyn, S.K. Yick, K.F. Dolman, Wear 256, 592-599 (2004)

2. S.D. Carpenter, D.E.O.S. Carpenter, J.T.H. Pearce, J. Alloys Compd. 494, 245-251 (2010)

3. S.D. Carpenter, D. Carpenter, J.T.H. Pearce, Mater. Chem. Phys. 85, 32-40 (2004)
4. ASM International, in Heat Treating, vol. 4 (ASM International, OH, 1997)

5. X.H. Tang, R. Chung, D.Y. Li, B. Hinckley, K. Dolman, Wear 267, 116-121 (2009)

6. D.B. Miracle, Compos. Sci. Technol. 65, 2526-2540 (2005)

7. G.L.F.F. Powell, J.V. Bee, J. Mater. Sci. 31, 707-711 (1996)

8. K. Abdel-Aziz, M. El-Shennawy, A.A. Omar, Int. J. Appl. Eng. Res. 12, 4675-4686 (2017)

9. M.A. Guitar, S. Suárez, O. Prat, M. Duarte Guigou, V. Gari, G. Pereira, F. Mücklich, J. Mater. Eng. Perform. 27, 3877-3885 (2018)

10. V. Efremenko, K. Shimizu, Y. Chabak, Metall. Mater. Trans. A Phys. Metall. Mater. Sci. 44, 5434-5446 (2013)

11. A.E. Karantzalis, A. Lekatou, H. Mavros, J. Mater. Eng. Perform. 18, 174-181 (2009)

12. G.L.F. Powell, G. Laird, J. Mater. Sci. 27, 29-35 (1992)

13. H. Gasan, F. Erturk, Metall. Mater. Trans. A Phys. Metall. Mater. Sci. 44, 4993-5005 (2013)

14. C.P. Tabrett, I.R. Sare, M.R. Ghomashchi, Int. Mater. Rev. 41, 59-82 (1996)

15. A. Wiengmoon, T. Chairuangsri, J.T.H. Pearce, ISIJ Int. 44, 396-403 (2004)

16. E. Karantzalis, A. Lekatou, H. Mavros, Int. J. Cast Met. Res. 22, 448-456 (2009)

17. A. Wiengmoon, J.T.H. Pearce, T. Chairuangsri, Mater. Chem. Phys. 125, 739-748 (2011)

18. M.A. Guitar, A. Scheid, S. Suárez, D. Britz, M.D. Guigou, F. Mücklich, Mater. Charact. 144, 621-630 (2018)

19. S. Johannes, E.F. Ignacio Arganda-Carreras, V. Kaynig, M. Longair, T. Pietzsch, S. Preibisch, C. Rueden, S. Saalfeld, B. Schmid, J.-Y. Tinevez, D.J. White, V. Hartenstein, K. Eliceiri, P. Tomancak, A. Cardona, Nat. Methods 9, 676-682 (2012)

20. J. Ayache, L. Beaunier, J. Boumendil, G. Ehret, D. Laub, Sample Preparation Handbook for Transmission Electron Microscopy, vol. 136 (Springer, Berlin, 2007)

21. M.A. Guitar, A. Scheid, D. Britz, F. Mücklich, Prakt. Metallogr. 56, 1-16 (2019)

22. C.P. Tabrett, I.R. Sare, Metall. Mater. Trans. A 26, 357-370 (1995)

23. Ö.N. Doğan, J.A. Hawk, G. Laird, Metall. Mater. Trans. A Phys. Metall. Mater. Sci. 28, 1315-1328 (1997)

24. B.A. Senior, Mater. Sci. Eng. A 103, 263-271 (1988)

25. A. Inoue, T. Masumoto, Metall. Trans. A 11, 739-747 (2007)

26. A.E. Karantzalis, A. Lekatou, E. Diavati, J. Mater. Eng. Perform. 18, 1078-1085 (2009) 
27. J. Wang, J. Xiong, H. Fan, H.-S. Yang, H.-H. Liu, B.L. Shen, J. Mater. Process. Technol. 209, 3236-3240 (2009)

28. A. Bedolla-Jacuinde, L. Arias, B. Hernández, J. Mater. Eng. Perform. 12, 371-382 (2003)
Publisher's Note Springer Nature remains neutral with regard to jurisdictional claims in published maps and institutional affiliations. 